\title{
Effect of statistically stored dislocations in tungsten on the irradiation induced nano-hardening analyzed by different methods
}

\author{
G. Bonny ${ }^{\mathrm{a}, *}$, T. Khvan ${ }^{\mathrm{a}, \mathrm{b}}$, A. Bakaeva ${ }^{\mathrm{a}}$, C. Yin ${ }^{\mathrm{a}, \mathrm{c}}$, A. Dubinko ${ }^{\mathrm{a}}$, C. $^{\mathrm{C}}$ Cabet $^{\mathrm{d}}$, M. Loyer-Prost $^{\mathrm{d}}$, \\ N. Castin ${ }^{a}$, A. Bakaev ${ }^{a}$, D. Terentyev ${ }^{a}$ \\ a SCK CEN, Nuclear Materials Science Institute, Boeretang 200, B-2400 Mol, Belgium \\ ${ }^{\mathrm{b}}$ University of Liège, Place du 20 Août 7, B-4000 Liège, Belgium \\ ${ }^{c}$ Université Catholique de Louvain, Institute of Mechanics, Materials and Civil Engineering, Louvain-la-Neuve 1348, Belgium \\ ${ }^{\mathrm{d}}$ Université Paris-Saclay, CEA, Service de Recherches de Métallurgie Physique, Laboratoire JANNUS, 91191, Gif-sur-Yvette, France
}

\section{A R T I C L E I N F O}

\section{Article history:}

Received 4 April 2020

Revised 15 September 2020

Accepted 20 September 2020

Available online 23 September 2020

\section{Keywords:}

Ion irradiation

Nanoindentation

Tungsten

\begin{abstract}
A B S T R A C T
Tungsten self-ion irradiation was performed at $800{ }^{\circ} \mathrm{C}$ up to $0.01-1 \mathrm{dpa}$ on two different $\mathrm{W}$ grades with essentially different dislocation density. Nanoindentation was applied to characterize the radiation hardening in two W grades with different microstructure. Different methods to analyze the indentation curves were applied to extract the bulk equivalent radiation hardening. It was shown that depending on the applied method, different outcomes may occur. The most satisfactory procedure was established and a consistent set of parameters was found. The bulk equivalent radiation hardening was found to saturate above $0.1 \mathrm{dpa}$. The characteristic distance between irradiation induced defects acting as dislocation pinning points was found to decrease up to $0.1 \mathrm{dpa}$, and then saturate/increase with irradiation dose. No essential difference in radiation hardening was observed between the studied $\mathrm{W}$ grades with essentially different initial dislocation density.
\end{abstract}

(C) 2020 SCK CEN, Belgian Nuclear Research Centre. Published by Elsevier B.V. All rights reserved.

\section{Introduction}

Tungsten (W), tungsten based alloys and composites are considered as armor material for plasma facing components in fusion applications [1-3]. Such components are exposed to a high heat flux (10 $\mathrm{MW} / \mathrm{m}^{2}$ average and $15-20 \mathrm{MW} / \mathrm{m}^{2}$ peak load), high neutron flux (leading to 3-5 dpa/fpy) with hard spectrum (14 MeV) and high energy particles present in the plasma. To withstand these extreme conditions, $\mathrm{W}$ was chosen as a base material owing to its high strength, high melting point, high thermal conductivity and low sputtering yield [1-3].

However, $\mathrm{W}$ is an inherently brittle material with high ductileto-brittle transition temperature $\left(300-400{ }^{\circ} \mathrm{C}\right)$ [4], and further hardens and embrittles when exposed to neutron irradiation [512]. For the applications as armor in the plasma facing components, W is not exposed to structural loads. However, it is exposed to cyclic heat loads that induce mechanical stresses, which in turn can lead to cracks in the components [13,14]. The extension of such cracks through the armor may cause rupture of the cooling pipe, causing a loss of vacuum accident [15]. Hence, the mechan-

\footnotetext{
* Corresponding author.

E-mail addresses: gbonny@sckcen.be, giovanni.bonny@gmail.com (G. Bonny).
}

ical properties of $\mathrm{W}$ do play a role, even though it acts as armor material.

To assess the mechanical response of $\mathrm{W}$ to neutron irradiation, large-scale irradiation campaigns in materials test reactors (MTR) are necessary [16]. However, such irradiation campaigns are very costly, lengthy and technically complex. It is thus unfeasible to characterize all relevant $\mathrm{W}$ grades under the complete matrix of irradiation conditions reflecting the nuclear fusion environment, using MTR solely. A cheaper alternative that allows larger screening campaigns, is the use of ion-irradiation facilities in combination with the nanoindentation technique to provide an initial assessment of the mechanical response to the irradiation mimicking fast neutrons.

In the literature, many authors have studied the impact of ion irradiation on the developed micro-mechanical properties for several $W$ grades and irradiation conditions [17-21]. In particular, the works by Zhang et al. [17,18] studied the effect of initial grain size on the resulting radiation hardening and found that the larger grain $\mathrm{W}$ is more susceptible to radiation hardening. At the same time, the investigation of the impact of high flux plasma exposure and high temperature annealing on $\mathrm{W}$ was also successfully studied by nanoindentation $[22,23]$. Some recent works have addressed the application of nanoindentation in combination with empirical and deterministic finite element modelling applied to $\mathrm{W}[24,25]$. 
The present work aims to complement the above-mentioned studies by investigating the impact of the self-ion irradiation on the evolution of irradiation induced hardening. In particular, here, we investigate the role played by initial dislocation density, also known as statistically stored dislocations (SSD). The question on the role played by the dislocation density arises from the hypothesis that materials with enhanced dislocation density should be more resistant to the radiation damage as dislocation lines act as sinks for mobile nano- and subnano-scale irradiation defects, thereby suppressing the resulting hardening [26].

Our earlier works have shown that the initial dislocation density plays a very important role in the trapping and release of hydrogen and helium in $\mathrm{W}$ studied under ITER-relevant plasma exposure conditions [27-30]. The initial dislocation network creates additional trapping sites and promotes strong trapping, which should be seen as a negative impact. Given that recently, heavy plastic deformation was successfully applied to develop ductile tungsten-copper composites [31], the question of how enhanced dislocation density may (or not) alter the evolution of microstructure and subsequent hardening induced by irradiation became very important.

In this work, we employ chemically identical $\mathrm{W}$ grades with same grain size but essentially different dislocation density, which is achieved by controlled plastic deformation. W samples were irradiated with $18 \mathrm{MeV}$ self-ions at the JANNuS irradiation facility [32]. Three irradiation doses were considered in the range 0.01-1 dpa, thereby spanning three orders of magnitude. The irradiations were performed at $800{ }^{\circ} \mathrm{C}$, which corresponds to the temperature of peak swelling [33] and thus a large change of the mechanical response is expected [34].

The radiation hardening is characterized by instrumented hardness tests performed using the nanoindentation technique. In the literature, many different approaches to analyze indentation curves are described [18,35-39]. As a complication, different approaches often lead to essentially different values of the deduced radiation hardening. Therefore, as a part of the present work, different approaches to analyze the indentation curves are applied and their approximations and assumptions discussed. As a conclusion, the most consistent procedure, following the authors, is highlighted.

\section{Experimental procedure}

\subsection{Materials}

Samples were prepared from hot-rolled polycrystalline tungsten (W) with a purity of 99.97 wt.\% manufactured by Plansee (Austria). The samples underwent the treatment described in $[40,41]$. In short, the samples were recrystallized at $1600{ }^{\circ} \mathrm{C}$ for $1 \mathrm{~h}$ in vacuum $\left(2-5 \times 10^{-4}\right.$ mbar $)$ at Forschungszentrum Jülich.

This procedure led to a $\mathrm{W}$ grade, henceforth $\mathrm{RX}$, with grain size in the range $10-50 \mu \mathrm{m}$ with dislocation density $(5.1 \pm 1.7) \times 10^{12}$ $\mathrm{m}^{-2}[40,41]$. To increase the dislocation density in the grains, part of the samples were plastically deformed at $600{ }^{\circ} \mathrm{C}$ up to an engineering strain of $22 \%$ (see $[40,41]$ for a detailed description) at SCK CEN. The obtained $\mathrm{W}$ grade, henceforth $\mathrm{RX}-22$, has the same grain size as RX, but with increased dislocation density $(8 \pm 3) \times 10^{13}$ $\mathrm{m}^{-2}$.

From these materials, the final samples were cut to the dimensions $4 \times 4 \times 0.3 \mathrm{~mm}^{3}$ via electrical discharge machining (EDM). The EDM cuts were made "gently" (i.e., in slowest mode possible) with a thin wire $(20 \mu \mathrm{m})$ to minimize damage to the surface.

Finally, mechanical polishing was applied to remove at least 50 $\mu \mathrm{m}$ of the surface to ensure that the EDM damage is completely removed. In particular, grinding was performed with Struers silicon carbide (SiC) polishing papers with grits of 220,500, 1200, 2000 and 4000. Each step was performed until the scratches induced

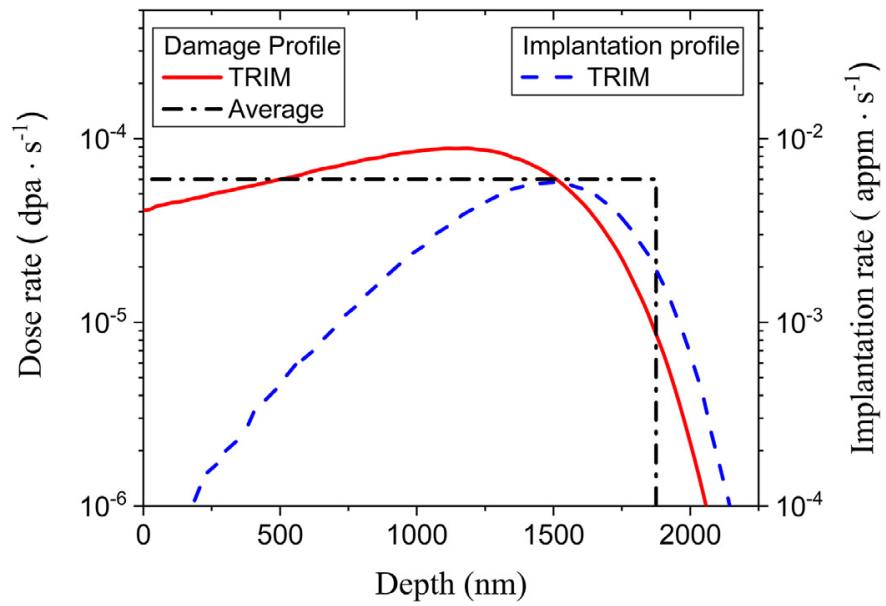

Fig. 1. Simulated damage and implantation profile for $18 \mathrm{MeV}$ self-ions in W, estimated using the Kinchin-Pease formalism as implemented in TRIM [42,43], with a $90 \mathrm{eV}$ threshold displacement energy [44].

during the previous step were removed. To finalize, polishing with diamond polishing suspension with diamond grain size of $3 \mu \mathrm{m}$ and $1 \mu \mathrm{m}$ were used.

\subsection{Ion-irradiation}

High energy self-ion irradiation was performed at the JANNuS irradiation facility [32]. The Epiméthée accelerator with $18 \mathrm{MeV}$ W ion beam was used to irradiate the samples. Three different irradiation doses were obtained during a single session by varying the exposure times, as described in Table 1 . The exposure time was controlled by shielding part of the samples with a movable mask. The irradiation was performed at $800{ }^{\circ} \mathrm{C}$ using active temperature control under a vacuum of $\sim 2 \times 10^{-7}$ mbar.

The samples temperature was directly monitored by a thermocouple in contact with one sample and by a thermal camera. No additional heating due to the beam was recorded as the thermal flux was low $\left(0.08 \mathrm{~W} / \mathrm{cm}^{2}\right)$. No obvious change of sample surface was observed after irradiation.

The irradiation temperature of $800{ }^{\circ} \mathrm{C}$ was selected as this is the temperature at which peak swelling is expected [33]. As such, outspoken radiation hardening is expected, which facilitates the comparison between the two different $\mathrm{W}$ grades. High energy $18 \mathrm{MeV}$ $\mathrm{W}$ ions were chosen to obtain a damage profile that is as uniform as possible up to a depth of a few $\mu \mathrm{m}$. As such, surface effects are minimized and an irradiation induced microstructure as close as possible to bulk irradiation is realized.

In Fig. 1, the damage and implantation profile is estimated for $18 \mathrm{MeV}$ self-ions. Both profiles were estimated using the KinchinPease formalism as implemented in TRIM [42,43], with a $90 \mathrm{eV}$ threshold displacement energy [44]. The maximum dose rate is achieved around $1.2 \mu \mathrm{m}$, and is at most a factor two higher than the dose rate at the free surface. At $\sim 1.9 \mu \mathrm{m}$, the dose rate is an order of magnitude lower than the maximum dose rate. Therefore, beyond this distance the dose rate is considered negligible. Thus, assuming the penetration depth, $d_{\text {irr }}=1.9 \mu \mathrm{m}$, the average dose rate for the simulated profile is indicated by the rectangular area in Fig. 1. The maximum ion implantation rate is found around $1.5 \mu \mathrm{m}$, which is within the same range of the damage profile. The implanted ions (in the form of self-interstitial atoms) are expected to bias interstitial dislocation loop growth. Practically, the implanted ions are expected to make the radiation profile less homogeneous. 
Table 1

Summary of the applied irradiation times, ion flux and fluence, and average accumulated dose (up to $1.9 \mu \mathrm{m}$ ).

\begin{tabular}{llll}
\hline Ion flux $\left(\times 10^{10}\right.$ ions $\left.\cdot \mathrm{cm}^{-2} \cdot \mathrm{s}^{-1}\right)$ & Irradiation time $(\mathrm{min})$ & Ion fluence $\left(\times 10^{13}\right.$ ions $\left.\cdot \mathrm{cm}^{-2}\right)$ & Average dose $(\mathrm{dpa})$ \\
\hline 3.0 & 3 & 0.5 & $0.01 \pm 0.003$ \\
3.0 & 30 & 5.4 & $0.1 \pm 0.03$ \\
3.0 & 303 & 54 & $1 \pm 0.3$ \\
\hline
\end{tabular}
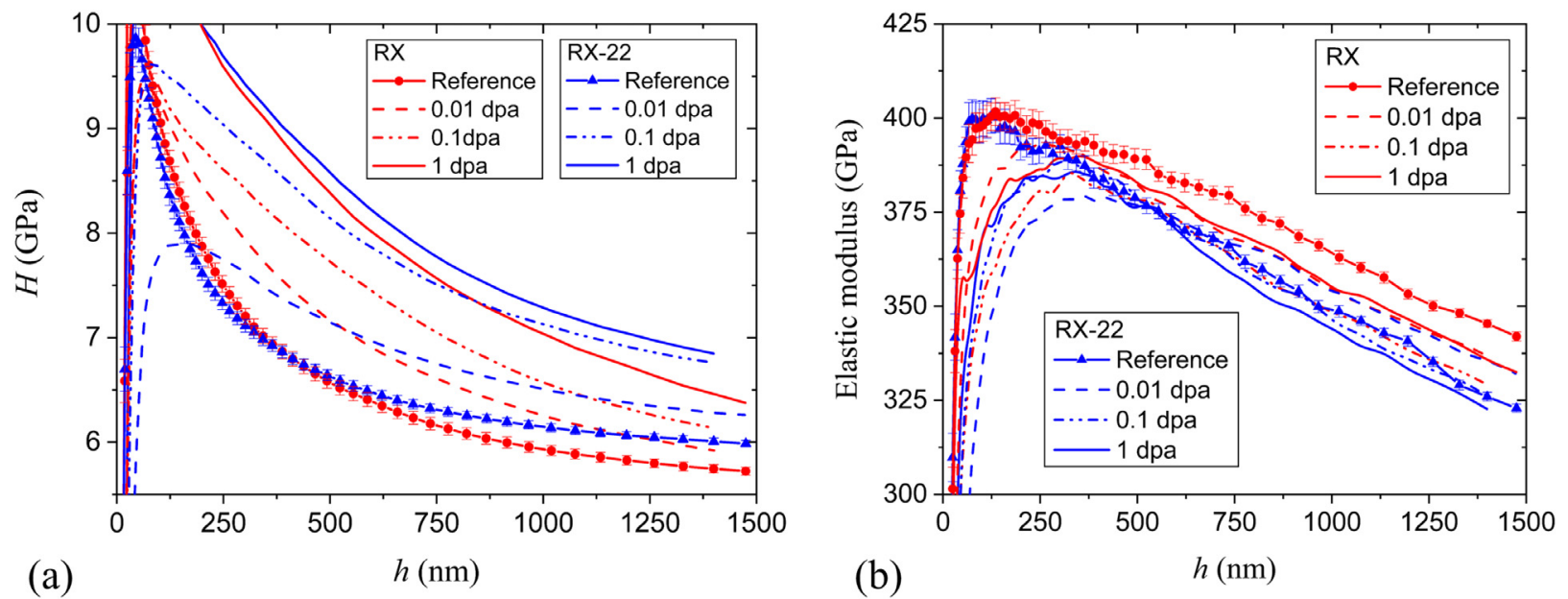

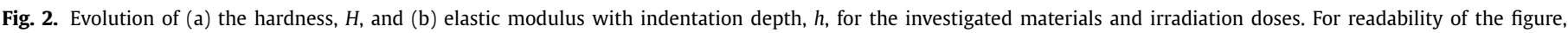
only the error bars for the reference curves were added. The error bars for the other curves are of similar magnitude.

\subsection{Nanoindentation}

Instrumented nanoindentation was performed using the Keysight G200 nanoindenter. All measurements were performed at room temperature in continuous stiffness mode (CSM) with a standard XP head equipped with Berkovich diamond tip.

The specimens were indented up to a penetration depth $h_{\max }=$ $1.5 \mu \mathrm{m}$, with the strain rate $0.05 \mathrm{~s}^{-1}$. For each sample, measurements on a grid of $5 \times 5$ indents, with $40 \mu \mathrm{m}$ spacing between them were performed. The averaged load-displacement curve was then used to calculate the elastic modulus and hardness using the Oliver and Pharr method [45].

The indenter tip and load frame calibration was performed by indenting a piece of silica. The obtained data were then used to align the value of the nominal elastic modulus.

\section{Results and discussion}

\subsection{Indentation curves}

The measured hardness, $H$, and elastic modulus as a function of indentation depth, $h$, for the investigated materials and irradiation doses is presented in Fig. 2. Each presented curve is the result of the average of 25 independently measured curves. As shown in Fig. 2a, $H$ decreases with $h$ starting from the critical depth, $h_{c}=50-160 \mathrm{~nm}$, depending on the material and irradiation dose. This decrease is known as the indentation size effect (ISE) and is explained by the theory of Nix and Gao [46]. For $h<h_{c}$, the indentation curves do not satisfy ISE because of uncertainties in the indenter- and sample surface geometry. It is important to note that different irradiation doses lead to different ISE and $h_{c}$.

As shown in Fig. 2b, for the elastic modulus a similar ISE is observed with values in the range 400-325 GPa. These values are significantly lower than the standard values 390-410 GPa reported in the literature [47]. Similar ISE effects were also observed for the unirradiated reference materials reported in the work by Krimpalis et al. [48], as well as for both irradiated and unirradiated materials in the work by Hasenhuetl et al. [49]. Following Hasenhuetl et al. [49], the ISE of the elastic modulus is attributed to pile-up effects that affect the actual indentation contact area.

Globally, at the same depth, the elastic modulus varies by no more than $10 \%$, regardless the $\mathrm{W}$ grade and irradiation doses. As expected, neither the initial dislocation density nor radiation damage modifies the elastic properties of the material.

The evolution of the radiation hardening, $\Delta H=H_{\text {irr }}-H_{\text {ref }}$, as function of $h$ for the investigated materials and irradiation doses is presented in Fig. 3. Clearly, radiation hardening is observed, which seems to increase with irradiation dose. However, due to differences in ISE, it is difficult to quantify the radiation hardening. To quantify the radiation hardening beyond the qualitative analysis provided in Fig. 3, a deeper analysis of the indentation curves is necessary.

Ideally, the radiation hardening must be judged based on the bulk equivalent hardness of both unirradiated reference and irradiated material. The next sections are dedicated to the accurate quantitative estimation of the latter, with well-controlled assumptions and approximations.

\subsection{Data analysis: isolated irradiation affected zone}

To describe the ISE, the theory by Nix and Gao [46] assumes a plastically deformed zone with the shape of a hemi-sphere under the indenter. In this zone, so-called geometrically necessary dislocations (GND) are generated to accommodate the indentation. By considering the interaction between SSD and GND, the following depth relation for the hardness is obtained,

$H=H_{0} \sqrt{1+\frac{h^{*}}{h}}$,

with $H_{0}$ the hardness at infinite depth (i.e., bulk equivalent hardness) and $h^{*}$ a characteristic length that describes the distance between obstacles pinning the GND. The aim of the present section is to evaluate the radiation hardening based on the bulk equivalent hardness, $\Delta H_{0}=H_{0}^{\mathrm{irr}}-H_{0}^{\mathrm{ref}}$. Thereby the aim is to select an inden- 

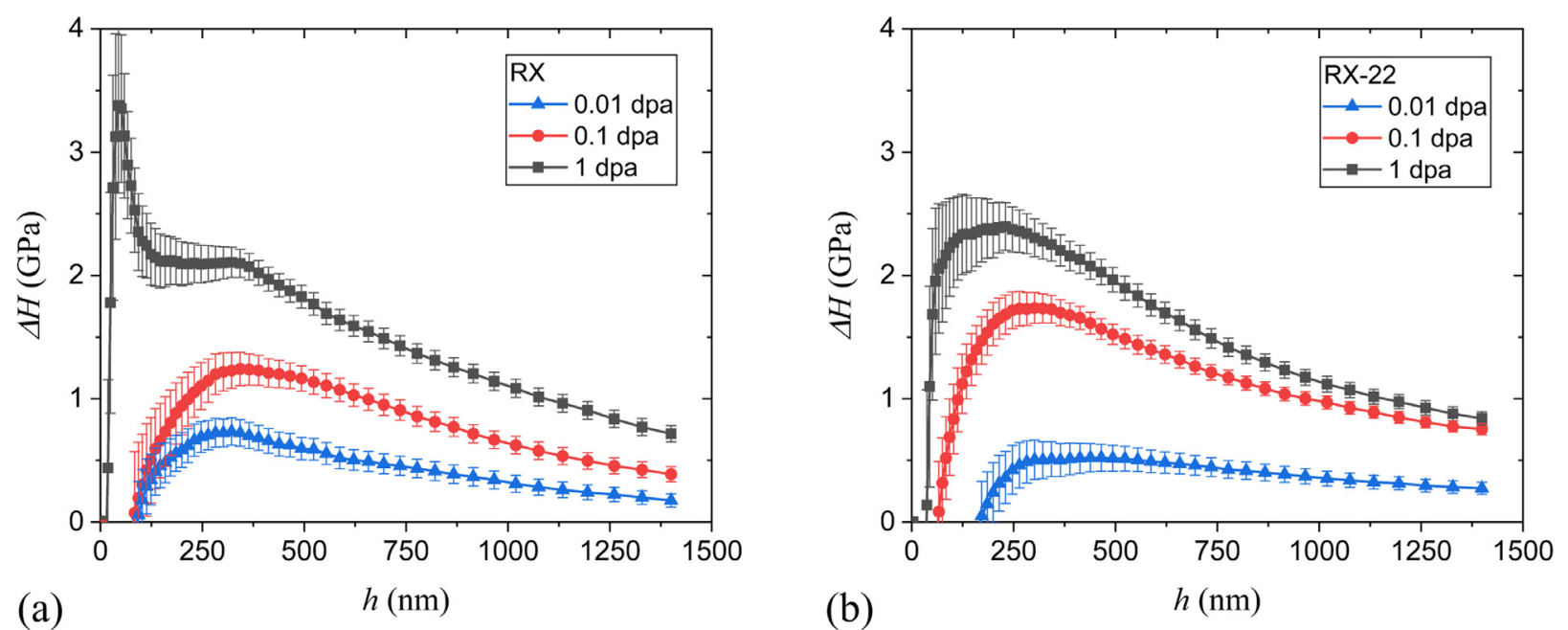

Fig. 3. Evolution of radiation hardening, $\Delta H=H_{\text {irr }}-H_{\text {ref }}$, as function of $h$ for all investigated materials and irradiation doses.
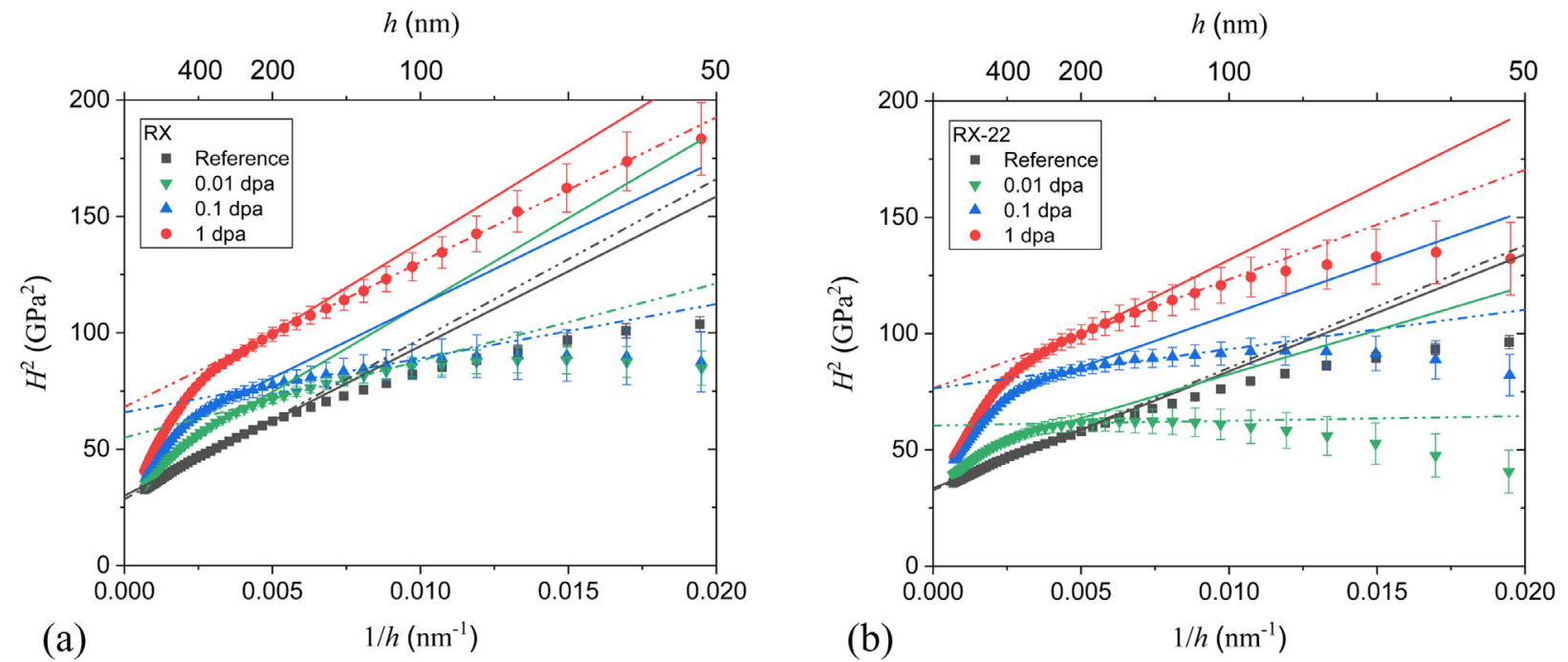

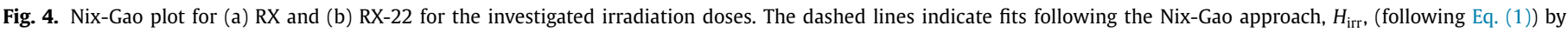
isolating the irradiation affected zone. The full lines indicate fits following the volume weighted average approach, $H_{m}$, (following Eq. ( 3 )).

tation depth range such that only the irradiation affected zone contributes to $H_{0}^{\mathrm{irr}}$.

Typically, Eq. (1) is fitted via so-called Nix-Gao plots, where $H^{2}$ is plotted versus $h^{-1}$ and both $H_{0}$ and $h^{*}$ are derived from the linear fit. The Nix-Gao plots for the investigated materials and irradiation doses are presented in Fig. 4.

For the unirradiated materials, a single slope is identified for $h^{-1} \leq h_{c}^{-1}$ (or $h \geq h_{c}$ ), with $h_{c}^{-1}=0.006 \mathrm{~nm}^{-1}$ (or $\left.h_{c}=160 \mathrm{~nm}\right)$ a critical indentation depth. The region $h^{-1}>h_{c}^{-1}$ (or $h<h_{c}$ ) corresponds to the part of the indentation curve that is not described by ISE due to uncertainties in indenter- and sample surface geometry. The fit of Eq. (1) in the region $h^{-1} \leq h_{c}^{-1}$ (or $h \geq h_{c}$ ) yields the values $5.34 \mathrm{GPa}$ and $5.72 \mathrm{GPa}$ for $H_{0}$; and $241 \mathrm{~nm}$ and $161 \mathrm{~nm}$ for $h^{*}$; for RX and RX-22, respectively (see also Table 2). The higher $H_{0}$ and lower $h^{*}$ values for RX-22, compared to RX, are consistent with the higher dislocation density. Indeed, it can be shown that $h^{*-1}$ is proportional to the density of SSD in the material (i.e., the dislocation density) $[46,50,51]$.

For the irradiated materials, the approach by Kasada et al. [35] is followed. In this approach, the ion-irradiated sample is considered as a thin film (i.e. damaged zone) on a substrate (i.e. unirradiated material). Therefore, for the irradiated materials, two slopes can be identified: one corresponding to $H$ related to the irradiated film and one associated to the combined effect of the irradiated film and underlying unirradiated substrate.

In this approach, the zone corresponding to the irradiated surface layer is estimated visually. To isolate the radiation effects, Eq. (1) is fitted in the range $h_{s}^{-1} \leq h^{-1} \leq h_{c}^{-1}$ (or $h_{c} \leq h \leq h_{s}$ ), with $h_{s}^{-1}$ the transition point in the Nix-Gao plot indicating the border between $H$ from the irradiated film only and $H$ from the combination of the irradiated film and unirradiated underlying substrate. From visual inspection of Fig. 4, the critical depth and transition point are identified around $h_{c}^{-1} \approx 0.01 \mathrm{~nm}^{-1}$ and $h_{s}^{-1} \approx 0.004 \mathrm{~nm}^{-1}$ (or $h_{c} \approx 100 \mathrm{~nm}$ and $h_{s} \approx 230 \mathrm{~nm}$ ), respectively. The results of this fitting procedure are summarized in Table 2 and indicated by the dashed lines in Fig. 4. As such, $H_{0}$ and $h^{*}$ for the irradiated film are determined as if the material was bulk irradiated (the results are discussed in the following section).

Clearly, this procedure is not very robust, as $h_{c}$ and $h_{s}$ are identified by visual inspection. Because of this, ambiguities introduced by this will propagate in the resulting $H_{0}$ and $h^{*}$. For example, while $h_{c}$ and $h_{s}$ can be identified with a certain confidence for both 0.1 and $1 \mathrm{dpa}$, the choice for $0.01 \mathrm{dpa}$ seems rather arbitrary. 
Table 2

Comparison of the fitted parameters following the volume weighted average approach and standard Nix-Gao approach on the isolated irradiation affected zone.

\begin{tabular}{|c|c|c|c|c|c|c|c|}
\hline \multirow[t]{2}{*}{ Material } & \multirow[t]{2}{*}{ Condition } & \multicolumn{2}{|l|}{$H_{0}(\mathrm{GPa})$} & \multicolumn{2}{|l|}{$h^{*}(\mathrm{~nm})$} & \multicolumn{2}{|l|}{$R$} \\
\hline & & Nix-Gao & vol. avg. & Nix-Gao & vol. avg. & Nix-Gao & vol. avg. \\
\hline \multirow[t]{4}{*}{$\mathrm{RX}$} & reference & 5.34 & 5.48 & 241 & 214 & - & - \\
\hline & $0.01 \mathrm{dpa}$ & 7.42 & 6.11 & 60 & 200 & 8.30 & 6.01 \\
\hline & 0.1 dpa & 8.11 & 7.04 & 35 & 126 & & \\
\hline & $1 \mathrm{dpa}$ & 8.25 & 7.81 & 91 & 128 & & \\
\hline \multirow[t]{4}{*}{$\mathrm{RX}-22$} & reference & 5.72 & 5.79 & & 150 & - & - \\
\hline & $0.01 \mathrm{dpa}$ & 7.78 & 6.68 & 3 & 85 & 8.30 & 6.02 \\
\hline & $0.1 \mathrm{dpa}$ & 8.74 & 7.96 & 22 & 71 & & \\
\hline & $1 \mathrm{dpa}$ & 8.74 & 8.25 & 61 & 93 & & \\
\hline
\end{tabular}
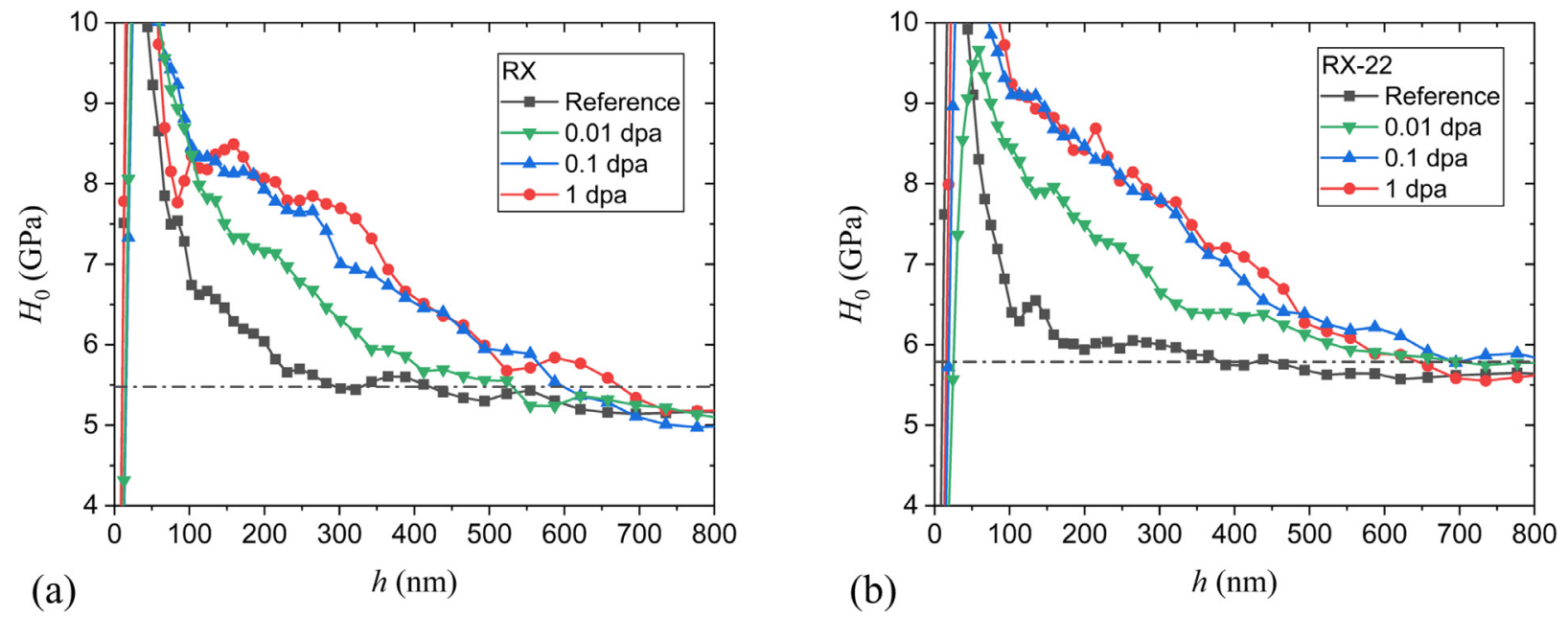

Fig. 5. Bulk equivalent $H_{0}(h)$ as a function of indentation depth for the investigated materials and irradiation doses.

To further illustrate possible inaccuracies following this procedure, even for unirradiated materials, in the following $H_{0}$ is determined at every $h$ following the approach by Kasada et al. [36]. In this approach, the bulk equivalent hardness at each indentation depth, $H_{0}(h)$, is evaluated as the intercept of the linear fitting based on the gradient of the Nix-Goa plot in point $h$. Application of this leads to the expression,

$H_{0}(h)=\sqrt{H^{2}(h)-h^{-1} \frac{d H^{2}(h)}{d\left(h^{-1}\right)}}$.

The resulting curves from applying Eq. (2) are plotted in Fig. 5 for the investigated materials and irradiation doses. For the unirradiated materials, $H_{0}(h)$ converges to the constant values $5.48 \mathrm{GPa}$ and 5.79 GPa for RX and RX-22, respectively. These values are in good agreement with the values obtained from the Nix-Gao plots.

However, somewhat surprisingly, $H_{0}(h)$ only converges from $h \geq 200 \mathrm{~nm}$, which is larger than the values $\left(h_{c}\right)$ estimated from Figs. 2 and 4. Especially for RX, some unexpected hardening is observed in the region $100-200 \mathrm{~nm}$. The latter is possibly the result of surface hardening due to the mechanical polishing of the sample surface. Similar effects were observed by Saleh et al. [38] in stainless steels.

Thus, based on these results, $h_{c}=200 \mathrm{~nm}$ seems to be a more appropriate choice. However, with $h_{c}=200 \mathrm{~nm}$ and $h_{s} \approx 230 \mathrm{~nm}$, too few data are available to reliably fit $H_{0}$ and $h^{*}$. Moreover, in many works, $h_{s}$ is not determined unambiguisly as it was estimated visually. An improvement on the estimation of $h_{s}$ could be the application of the method by Hudson [52], where the most likely transition points between segmented curves are derived from statistical analyses. However, this refinement is outside the present scope of this study.
From Fig. 5, it is observed that for the irradiated materials, $H_{0}(h)$ converges to the values of the unirradiated ones at a depth in the range $400-600 \mathrm{~nm}$. Thus, beyond $400-600 \mathrm{~nm}$, the contribution of the irradiated film to the hardness becomes negligible compared to the contribution of the unirradiated substrate. Thus, a region with width $200-400 \mathrm{~nm}$, rather than $30 \mathrm{~nm}$, containing useful data to determine $H_{0}$ and $h^{*}$ is available. However, corrections for contributions of the unirradiated substrate will need to be accounted for. In the following section, such an approach is applied.

\subsection{Data analysis: volume weighted average}

In the approach by Hosemann et al. [37], the measured hardness, $H_{m}$, is decomposed as the volume-weighted average of the hardness of the unirradiated material, $H_{\text {ref }}$, and irradiated material, $H_{\text {irr }}$, within the plastically affected zone,

$H_{m}=f_{\text {irr }} H_{\text {irr }}+\left(1-f_{\text {irr }}\right) H_{\text {ref }}$.

Here, $f_{\text {irr }}$ is the volume fraction of irradiated material in the plastically affected zone. Thus, given that $H_{\mathrm{irr}}$ satisfies ISE, $H_{0}^{\mathrm{irr}}$ and $h_{\mathrm{irr}}^{*}$ can be fitted by applying Eqs. (1) and (3).

Within the Nix-Gao model, the plastically affected zone under the indenter is assumed to be a hemi-sphere with radius $r=R h$, with $R$ a constant typically in the range 5-10 [24,51,53]. These values are supported by finite element calculations [24,38,51], but can also be estimated by correlating the maximum depth of the damage profile, $d_{\text {irr }}$, (see also Fig. 1 ) to the transition point, $h_{s}$, observed in the Nix-Gao plot (see also Fig. 4). With the values $d_{\text {irr }}=1.9 \mu \mathrm{m}$ and $h_{s} \approx 230 \mathrm{~nm}$, the constant $R \approx 8.3$ is obtained, which is within the expected range. However, it is noted that given the ambiguities 

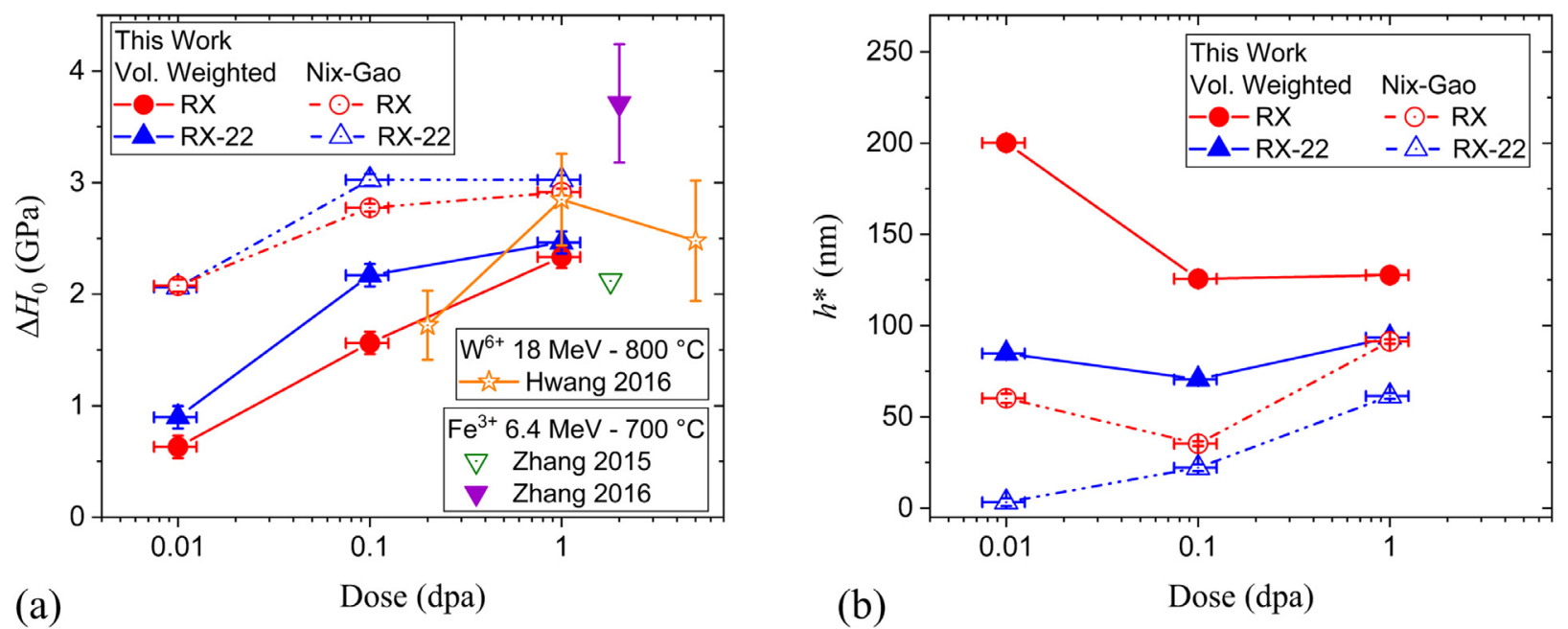

Fig. 6. (a) Bulk equivalent radiation hardening and (b) characteristic length between dislocation pinning points as a function of irradiation dose for both RX and RX-22.

in the estimation of $h_{s}$, and the theory as a whole with simplifications such as a hemispherical shape of the plastically affected zone, the obtained value for $R$ is considered as an indication rather than an accurate estimate.

The volume fraction of irradiated material within in the plastically affected zone is given as,

$f_{\mathrm{irr}}=\left\{\begin{array}{ll}1, & \text { for } r \leq d_{\mathrm{irr}} \\ \frac{d_{\mathrm{irr}}}{2 r^{3}}\left(3 r^{2}-d_{\mathrm{irr}}^{2}\right), & \text { for } r>d_{\mathrm{irr}}\end{array}\right.$.

Given the ambiguities in the estimation of $R$, in the present work, it was also used as a fitting parameter. The fitting procedure is described as follows.

For the given reference material (RX or RX-22), Eq. (1) was fitted to the indentation curves in the range $200 \mathrm{~nm} \leq h \leq 1500 \mathrm{~nm}$. As a result, the parameters $H_{0}^{\text {ref }}$ and $h_{\text {ref }}^{*}$ are obtained for RX and $\mathrm{RX}-22$, respectively.

Given $H_{0}^{\text {ref }}, h_{\text {ref }}^{*}$ and $d_{\text {irr }}=1.9 \mu \mathrm{m}$, Eq. (3) $\left(H_{\text {irr }}\right.$ is expressed via Eq. (1)) was fitted to the indentation curves in the range $200 \mathrm{~nm} \leq h \leq 1500 \mathrm{~nm}$ for all considered doses simultaneously (for $\mathrm{RX}$ or RX-22). As such, $H_{0}^{\mathrm{irr}}, h_{\mathrm{irr}}^{*}$ and $R$ were fitted simultaneously for all irradiation doses, but separately for RX and RX-22.

The results of this fitting procedure are presented in Table 2. For both RX and RX-22, the value $R=6.0$ was obtained, which is again within the expected range. The fact that RX and RX-22 were fitted independently and similar values for $R$ were obtained, strengthens the consistency of the followed approach.

It is noted that in the literature similar methods were applied taking into account the precise damage profile [39]. However, given the fact that the damage profile by itself is an estimation and the hemi-spherical shape of the plastically affected zone is an approximation, such an approach seems like an unnecessary complication for the present work.

In Fig. 6, the bulk equivalent radiation hardening, $\Delta H_{0}$ and $h^{*}$ for the investigated materials and irradiation doses are presented. To illustrate the sensitivity of the results to the different applied methods, the results obtained in Section 3.2 are also added to the figure. It should be noted that the error bars associated with $\Delta H_{0}$ and $h^{*}$ represent the statistical uncertainties associated to the fitted regression parameters. These error bars do not take the quality of the applied regression (i.e., model) into account.

Regardless the approach, significant radiation hardening is observed that increases with dose. With the Nix-Gao approach, the radiation hardening amounts to $36-55 \%$, while the radiation hardening obtained using the volume weighted average amounts to 12-
43\%. The radiation hardening is similar for both $\mathrm{RX}$ and $\mathrm{RX}-22$, with RX-22 being slightly higher than RX at $0.1 \mathrm{dpa}$. Thus, there is no apparent effect of variation of dislocation density by an order of magnitude on the irradiation induced hardening.

The radiation hardening following the approach in Section 3.2 shows clear saturation already from $0.1 \mathrm{dpa}$, while with the present approach the saturation is less outspoken, especially for RX. Also, the approach in Section 3.2 estimates $\Delta H_{0}$ to be systematically higher than the estimates using the volume weighted average approach. The difference between both approaches decreases with increasing dose: about a factor 3 for $0.01 \mathrm{dpa}$ and $\sim 1.3$ for $1 \mathrm{dpa}$. This observation can be explained as follows: with increasing dose, the difference in hardness between irradiated film and unirradiated substrate becomes larger; and the larger the hardness difference, the more accurate the estimate of $h_{s}$ and hence, fewer ambiguities enter the approach in Section 3.2.

For both materials, $h^{*}$ decreases with dose up to $0.1 \mathrm{dpa}$ (with one exception for $0.01 \mathrm{dpa}$ ), and saturates or increases with dose above it. Given the fact that $h^{*}$ is proportional to the mean distance between dislocation pinning points [18,46,50], this suggests that the radiation induced defect density saturates or decreases above $0.1 \mathrm{dpa}$. Consistent with the larger $\Delta H_{0}$ following the approach in Section 3.2, the associated $h^{*}$ is consistently lower than the one obtained following the volume weighted average approach.

The present results are consistent with the work by Hwang et al. [20], where technically pure $W$ was irradiated with 18 $\mathrm{MeV} \mathrm{W}^{6+}$ ions at $800{ }^{\circ} \mathrm{C}$ up $0.2-5.0 \mathrm{dpa}$. In that work, both void and loop density are reported to saturate in the range 15 dpa. The reported radiation hardening is added to Fig. 6a. However, in that work the followed post-processing procedure of the indentation curves is not reported. As the obtained radiation hardening is sensitive to the followed approach, an accurate comparison is not possible. It can only be stated that the data is within the range of the data reported in the present work.

In the works by Zhang et al. [17,18], as received and recrystallized technically pure $\mathrm{W}$ was irradiated with $6.4 \mathrm{MeV} \mathrm{Fe}^{3+}$ ions in the temperature range $300-1000{ }^{\circ} \mathrm{C}$ up to $2 \mathrm{dpa}$. The radiation hardening for recrystallized $\mathrm{W}$, with similar grain size as the materials studied here, irradiated at $700{ }^{\circ} \mathrm{C}$, is added to Fig. 6a. The two different data points were obtained from the same indentation curve, but analyzed by different approaches. The lowest value was obtained via the standard Nix-Gao analysis (similar to the approach followed in Section 3.2), while the highest value was ob- 
tained via a Nix-Gao analysis with modified summing rule of the stress.

Nevertheless, both methods rely on the visual identification of the range $h_{c} \leq h \leq h_{s}$, which induces ambiguities in the obtained radiation hardening. While both data points are within the range of the values reported in the present work, they mostly illustrate how different methods applied to the same indentation curve can lead to essentially different results for the bulk equivalent hardness.

\section{Conclusive remarks}

Tungsten self-ion irradiation was performed at $800{ }^{\circ} \mathrm{C}$ up to 0.01-1 dpa on two different $\mathrm{W}$ grades with essentially different dislocation density. Nanoindentation was applied to characterize the radiation hardening in the different $\mathrm{W}$ grades.

Different methods to analyze the indentation curves were applied to extract the bulk equivalent radiation hardening. It was shown that depending on the applied method, different outcomes might occur.

The most satisfactory procedure involves the following steps: i) determination of $H_{0}(h)$ for the reference unirradiated material to estimate the critical depth $h_{c}$, above which the uncertainties in indenter geometry/surface roughness are negligible; ii) least square fitting of the Nix-Gao parameters and ratio $R$ by applying the volume weighted average of the irradiated and unirradiated zones within the plastically affected volume for $h \geq h_{c}$; and iii) verification of the fitted ratio $R=r / h$ to ensure that it lays within reasonable limits.

This procedure was applied to the obtained indentation curves and a consistent set of parameters was found. The ratio, $R=6.0$, was found independently for both $\mathrm{W}$ grades. This ratio agrees well with the volume of the plastically induced region deduced by the application of finite element modelling for the nanoindentation conditions as studied here [24].

The bulk equivalent radiation hardening was found to saturate above $0.1 \mathrm{dpa}$. The characteristic distance between irradiation induced dislocation pinning points was found to decrease up to 0.1 $\mathrm{dpa}$, and then saturate/increase with irradiation dose.

No essential difference in radiation hardening was observed between the different $\mathrm{W}$ grades with essentially different initial dislocation density under the employed irradiation conditions, i.e., irradiation temperature of $800^{\circ} \mathrm{C}$ and dose rate of $6 \times 10^{-5} \mathrm{dpa} \cdot \mathrm{s}^{-1}$. This result suggests that the variation in the dislocation density within the range $5 \times 10^{12}-8 \times 10^{13} \mathrm{~m}^{-2}$ does not have a strong impact on the accumulation of radiation defects in commercially pure tungsten grades, fabricated following ITER specifications. Future investigations should address the impact of flux and test temperature, as in this study, the irradiation flux was essentially higher than the one expected in a fusion environment, while nanoindentation was performed at room temperature.

\section{Declaration of Competing Interest}

The authors declare that they have no known competing financial interests or personal relationships that could have appeared to influence the work reported in this paper.

\section{CRediT authorship contribution statement}

G. Bonny: Conceptualization, Methodology, Formal analysis, Funding acquisition, Project administration, Writing - original draft. T. Khvan: Data curation, Investigation, Writing - review \& editing. A. Bakaeva: Data curation, Investigation. C. Yin: Investigation. A. Dubinko: Investigation. C. Cabet: Resources, Writing - review \& editing. M. Loyer-Prost: Resources, Writing - review \& editing. N. Castin: Conceptualization, Writing - review \& editing. A.
Bakaev: Writing - review \& editing. D. Terentyev: Funding acquisition, Project administration, Writing - review \& editing.

\section{Acknowledgements}

This work has been carried out within the framework of the EUROfusion Consortium and has received funding from the Euratom research and training programme 2014-2018 and 20192020 under grant agreement No 633053. This work has received funding from the Euratom research and training programme 20142018 under grant agreement No. 755039 (M4F project). The views and opinions expressed herein do not necessarily reflect those of the European Commission. The financial support of FOD for fusion $\mathrm{R} \& \mathrm{D}$ is greatly acknowledged. The JANNuS technical staff is acknowledged for performing the irradiation experiments. The Hotlab technical staff at SCK CEN is acknowledged for technical support.

\section{References}

[1] S.J. Zinkle, Phys. Plasmas 12 (2005) 1-8.

[2] S. Matsuda, K. Tobita, J. Nucl. Sci. Technol. 50 (2013) 321-345.

[3] G. Federici, W. Biel, M.R. Gilbert, R. Kemp, N. Taylor, R. Wenninger, Nucl. Fusion 57 (2017) 092002.

[4] A. Giannattasio, Z. Yao, E. Tarleton, S.G. Roberts, Philos. Mag. 90 (2010) 3947-3959.

[5] A. Hasegawa, M. Fukuda, S. Nogami, K. Yabuuchi, Fusion Eng. Des. 89 (2014) 1568-1572.

[6] I.V. Gorynin, V.A. Ignatov, V.V. Rybin, S.A. Fabritsiev, V.A. Kazakov, V.P. Chakin, V.A. Tsykanov, V.R. Barabash, Y.G. Prokofyev, J. Nucl. Mater. 191-194 (1992) 421-425.

[7] J.M. Steichen, J. Nucl. Mater. 60 (1976) 13-19.

[8] I.V. Gorynin, V.A. Ignatov, V.V. Rybin, S.A. Fabritsiev, V.A. Kazakov, V.P. Chakin, V.A. Tsykanov, V.R. Barabash, Y.G. Prokofyev, J. Nucl. Mater. 191 (1992) 421-425.

[9] I. Alexandrov, I.V. Gorynin, Metallovedenie 22 (1979) 35.

[10] M. Fukuda, N.A.P.K. Kumar, T. Koyanagi, L.M. Garrison, L.L. Snead, Y. Katoh, A. Hasegawa, J. Nucl. Mater. 479 (2016) 249-254.

[11] M. Rieth, R. Doerner, A. Hasegawa, Y. Ueda, M. Wirtz, J. Nucl. Mater. 519 (2019) 334-368.

[12] D. Terentyev, M. Vilemova, C. Yin, J. Veverka, A. Dubinko, J. Matejicek, Int. J. Refract. Metals Hard Mater. 89 (2020) 105207

[13] G. Pintsuk, 4.17 - Tungsten as a plasma-facing material, in: R.J.M. Konings (Ed.), Comprehensive Nuclear Materials, Elsevier, Oxford, 2012, pp. 551-581.

[14] M. Li, J.-H. You, Fusion Eng. Des. 101 (2015) 1-8.

[15] D. Stork, P. Agostini, J.L. Boutard, D. Buckthorpe, E. Diegele, S.L. Dudarev, C. English, G. Federici, M.R. Gilbert, S. Gonzalez, A. Ibarra, C. Linsmeier, A. Li Puma, G. Marbach, P.F. Morris, L.W. Packer, B. Raj, M. Rieth, M.Q. Tran, D.J. Ward, S.J. Zinkle, J. Nucl. Mater. 455 (2014) 277-291.

[16] G. Pintsuk, E. Diegele, S.L. Dudarev, M. Gorley, J. Henry, J. Reiser, M. Rieth, Fusion Eng. Des. 146 (2019) 1300-1307.

[17] Z.X. Zhang, D.S. Chen, W.T. Han, A. Kimura, Fusion Eng. Des. 98-99 (2015) 2103-2107.

[18] Z. Zhang, E. Hasenhuetl, K. Yabuuchi, A. Kimura, Nucl. Mater. Energy 9 (2016) 539-546.

[19] I. Uytdenhouwen, T. Schwarz-Selinger, J.W. Coenen, M. Wirtz, Phys. Scr. T167 (2016) 014007

[20] T. Hwang, M. Fukuda, S. Nogami, A. Hasegawa, H. Usami, K. Yabuuchi, K. Ozawa, H. Tanigawa, Nucl. Mater. Energy 9 (2016) 430-435.

[21] D.E.J. Armstrong, X. Yi, E.A. Marquis, S.G. Roberts, J. Nucl. Mater. 432 (2013) 428-436.

[22] D. Terentyev, A. Bakaeva, T. Pardoen, A. Favache, E.E. Zhurkin, J. Nucl. Mater. 476 (2016) 1-4.

[23] L. Tanure, A. Bakaeva, A. Dubinko, D. Terentyev, K. Verbeken, J. Nucl. Mater. 524 (2019) 191-199.

[24] X.Z. Xiao, D. Terentyev, A. Ruiz, A. Zinovev, A. Bakaev, E.E. Zhurkin, Mat. Sci. Eng. Struct. 743 (2019) 106-113.

[25] D. Terentyev, X.Z. Xiao, S. Lemeshko, U. Hangen, E.E. Zhurkin, Int. J. Refract. Met. H 89 (2020) 105222.

[26] G.S. Was, Fundamentals of Radiation Materials Science, Springer, New York, 2007.

[27] D. Terentyev, G. De Temmerman, B. Minov, Y. Zayachuk, K. Lambrinou, T.W. Morgan, A. Dubinko, K. Bystrov, G. Van Oost, Nucl. Fusion 55 (2015) 013007.

[28] D. Terentyev, G. De Temmerman, T.W. Morgan, Y. Zayachuk, K. Lambrinou, B. Minov, A. Dubinko, K. Bystrov, G. Van Oost, J. Appl. Phys. 117 (2015) 083302.

[29] A. Bakaeva, D. Terentyev, G. De Temmerman, K. Lambrinou, T.W. Morgan, A. Dubinko, P. Grigorev, K. Verbeken, J. Noterdaeme, J. Nucl. Mater. 479 (2016) 307-315.

[30] A. Bakaeva, D. Terentyev, T.W. Morgan, A. Dubinko, W. van Renterghem, L. Tanure, K. Verbeken, Nucl. Mater. Energy 15 (2018) 48-54. 
[31] J. Reiser, S. Wurster, J. Hoffmann, S. Bonk, C. Bonnekoh, D. Kiener, R. Pippan, A. Hoffmann, M. Rieth, Int. J. Refract. Met. H 58 (2016) 22-33.

[32] A. Gentils, C. Cabet, Nucl. Instrum. Methods Phys. Res. Sect. B: Beam Interact. Mater.Atoms 447 (2019) 107-112.

[33] J. Matolich, H. Nahm, J. Moteff, Scr. Metall. 8 (1974) 837-841.

[34] G. Bonny, M.J. Konstantinovic, A. Bakaeva, C. Yin, N. Castin, K. Mergia, V. Chatzikos, S. Dellis, A. Bakaev, A. Dubinko, D. Terentyev, Trends in vacancy distribution and hardness of high temperature neutron irradiated single crystal tungsten, Acta Materialia 198 (2020) 1-9, doi:10.1016/j.actamat.2020.07.047.

[35] R. Kasada, Y. Takayama, K. Yabuuchi, A. Kimura, Fusion Eng. Des. 86 (2011) 2658-2661.

[36] R. Kasada, S. Konishi, K. Yabuuchi, S. Nogami, M. Ando, D. Hamaguchi, H. Tanigawa, Fusion Eng. Des. 89 (2014) 1637-1641.

[37] P. Hosemann, D. Kiener, Y. Wang, S.A. Maloy, J. Nucl. Mater. 425 (2012) $136-139$.

[38] M. Saleh, Z. Zaidi, M. Ionescu, C. Hurt, K. Short, J. Daniels, P. Munroe, L. Edwards, D. Bhattacharyya, Int. J. Plast. 86 (2016) 151-169.

[39] A. Kareer, A. Prasitthipayong, D. Krumwiede, D.M. Collins, P. Hosemann, S.G. Roberts, J. Nucl. Mater. 498 (2018) 274-281.

[40] M. Zibrov, M. Balden, M. Dickmann, A. Dubinko, W. Egger, M. Mayer, D. Terentyev, M. Wirtz, Nucl. Fusion 59 (2019) 106056
[41] A. Dubinko, in, Ghent University, Ghent, 2018, pp. 154.

[42] J.F. Ziegler, M.D. Ziegler, J.P. Biersack, Nucl. Instrum. Methods Phys. Res. Sect B: Beam Interact. Mater. Atoms 268 (2010) 1818-1823.

[43] J.F. Ziegler, J.P. Biersack, U. Littmark, The Stopping and Range of Ions in Solids, Pergamon Press, New York, 1985.

[44] Standard Practice for Neutron Radiation Damage Simulations by Charge Particle Irradiation, Annual Book of ASTM Standards, 1996.

[45] W.C. Oliver, G.M. Pharr, J. Mater. Res. 7 (1992) 1564-1583.

[46] W.D. Nix, H. Gao, J. Mech. Phys. Solids 46 (1998) 411-425.

[47] E.S.W.-D. Lassner, Tungsten, Properties, Chemistry, Technology of the Element, Alloys, and Chemical Compounds, Springer US, 1999.

[48] S. Krimpalis, K. Mergia, S. Messoloras, A. Dubinko, D. Terentyev, K. Triantou, J. Reiser, G. Pintsuk, Phys. Scr. T170 (2017) 014068.

[49] E. Hasenhuetl, R. Kasada, Z. Zhang, K. Yabuuchi, Y.-J. Huang, A. Kimura, Mater. Trans. 58 (2017) 749-756.

[50] S. Graça, R. Colaço, P.A. Carvalho, R. Vilar, Mater. Lett. 62 (2008) 3812-3814.

[51] K. Durst, B. Backes, M. Göken, Scr. Mater. 52 (2005) 1093-1097.

[52] D.J. Hudson, J. Am. Stat. Assoc. 61 (1966) 1097-1129.

[53] M. Mata, O. Casals, J. Alcalá, Int. J. Solids Struct. 43 (2006) 5994-6013. 